\title{
LOS CLÁSICOS EN LA FORMACIÓN LECTORA. TESTIMONIOS DE ESCRITORES
}

\author{
María Isabel LÓPEZ MARTÍNEZ \\ Universidad de Extremadura \\ milopez@unex.es
}

$\underbrace{1}$

acto de leer, y en correspondencia la escritura, es omnipresente en las sociedades avanzadas y supone la actividad medular en el ámbito de la enseñanza. Estudiar implica leer e interpretar desde fórmulas matemáticas o químicas hasta un libro de ficción. George Steiner (2001) señalaba en Después de Babel que los términos lectura e interpretación suelen ser sinónimos e incluso intercambiables con el concepto de traducción en tanto que es preciso descifrar y, en consecuencia, atraer los códigos leídos al sistema mental. Aunque el verbo leer se asocie a la actividad íntima de penetrar intelectualmente en los libros, su contenido se abre a procesos más latos. En la Universidad las actividades a favor de la lectura abarcan lo virtual y lo presencial, además de contar con proyectos transversales, algunos de ámbito internacional, cuyo reto es potenciar el papel de la lectura y la escritura no solo como instrumento de trabajo (la llamada alfabetización académica), sino como vehículo de promoción integral (Ramírez Leyva, 2015; Martos Núñez, Campos Fernández-Fígares, 2013).

Al abordar la lectura destinada a los estudiantes cabe plantarse cuál es la función de leer, asunto debatido desde antaño desde perspectivas muy variadas. En Confesiones de un joven novelista, ensayo de título paradójico que acomete Umberto Eco en plena senectud ya que fue publicado en 2011, el semiólogo de Bolonia modula el planteamiento ancestral de la literatura como singular y efectivo medio de conocimiento en tanto que brinda facetas del mundo solo accesibles por la mirada del autor, sin cuya guía pasarían desapercibidas para el común de los individuos. Parafraseando a Joseph Addison en Los placeres de la imaginación (1712), escribe Eco:

Bien escogidas, las palabras tienen tal fuerza en su interior que una descripción a menudo nos da una idea más viva que la visión de las propias cosas [...]. Se dice que cuando el Laocoonte fue descubierto en Roma en 1506, la gente lo reconoció como aquella famosa estatua griega por la descripción verbal facilitada por Plinio el Viejo en su Naturalis Historia» (2011: 33).

En estas afirmaciones resuenan ecos de la teoría que expuso V. Sklovski en el conocido artículo «El arte como artificio», que comienza remitiendo a una frase que Potebnia insertó en sus Notas sobre la teoría de la literatura (1905): «Al igual que la prosa, la poesía es sobre todo, y en 
primer lugar, una cierta manera de pensar y de conocer» (Sklovski en Todorov, 1991: 55-70). Sklovski sostiene que el automatismo perceptivo borra los rasgos singulares y, por el contrario, la literatura libera los objetos de tal automatismo, los singulariza al desvelar facetas inusitadas, abriendo así un territorio inesperado al conocimiento. Al aplicar al objeto palabras inusuales, se crea una percepción particular que ayuda a reconocerlo, como la estatua del Laocoonte referida por Eco (Skolvski en Todorov, 1991: 55-70). En De Oratore aducía Cicerón que el arte abarca las cosas de las que tenemos conocimiento, quae sciuntur (De Or. II, 7. 30), y se ha añadido que posee asimismo un poder revelador.

Cuando actúan las metáforas, tal hecho se confirma epistemológicamente. Por ejemplo, en el poema «Respiración» de Mundo dentro del claro (2012), así titulado por el sentido de iluminaciónrevelación que comporta la voz lírica, Vicente Gallego, sobre la plantilla de los poemas de definición próvidos en los Siglos de Oro, engarza imágenes del acto de inspirar y expirar. La respiración es «fuelle de la verdad» por su movimiento acompasado y por representar la vida; también es «corola del sosiego» porque los labios exhalando el aire antes inhalado aportan cierta calma en momentos de iracundia. Estas analogías tropológicas que establecen concomitancias entre una actividad humana, un objeto y un elemento de la flora proporcionan otra vía de acceso intelectual al ente primario a través de los respectivos rasgos semánticos similares.

La literatura ayuda a percibir la realidad de una manera más compleja y completa, porque su cobertura estética, indisoluble con el contenido, expresa visiones de mundo ajenas a la mirada común. Para ello, y continuando con los presupuestos del formalismo ruso que han seguido calando hasta en la teoría reciente, ha de forzar el lenguaje, provocar que supere los usos convencionales e incluso las normas en busca de prolongar y aquilatar la percepción (Senabre, 2015). En esta línea también se pronuncia Harold Bloom (2000) en Cómo leer y por qué cuando indica que el valor literario está asociado a lo útil, pues se vincula a la capacidad de revelación de una obra, a la intensidad con la que ilumina y hace comprensibles las facetas de nuestra experiencia y de nuestros nexos con los demás y con el mundo ${ }^{1}$.

Tres siglos antes, Baltasar Gracián en Oráculo manual y arte de prudencia recomendaba la idoneidad de la lectura en la juventud, etapa de la constitución del ser: «Gástese la primera estancia del bello vivir en hablar con los muertos: nacemos para saber y sabemos, y los libros con fidelidad nos hacen personas» (Gracián, 1969: n 229). Además de la última apreciación sobre el papel de la lectura en la forja de la identidad, coincide con Quevedo al plantear la equivalencia entre leer y «hablar con los muertos», expuesta en el bellísimo soneto cuyo cuarteto de arranque es: «Retirado en la paz de estos desiertos, / con pocos, pero doctos libros juntos, / vivo en conversación con los difuntos, / y escucho con mis ojos a los muertos». El diálogo con seres del pasado y el acceso a experiencias consumadas pero aún vigentes constituyen un poderoso utillaje para la forja de la identidad personal. A la imagen de la lectura como conversación con los muertos, se añade otra

\footnotetext{
${ }^{1}$ Para una crítica de la postura de H. Bloom en este libro, véase Aullón de Haro, 2013:55. Critica la superficialidad de Bloom al tratar las obras que presenta, de las que lanza simples comentarios o paráfrasis.
} 
metáfora aclaradora, el viaje mistérico, tantas veces arduo y osado, que acomete el lector hacia el encuentro con lejanas voces que emergen del libro como sombras (García Gual, 1998).

En una reflexión titulada Por qué leer a los clásicos Italo Calvino (1996) ofrece catorce respuestas a tan crucial pregunta. Se plantea el sentido de la lectura en la juventud poniendo la lente en el provecho que aporta, probablemente escaso -según él- por impaciencia, distracción, desconocimiento del sistema literario y falta de vivencias del lector púber. No obstante, destaca que los libros proporcionan modelos futuros relativos a contenidos, valores y paradigmas de belleza, acumulando posos que seguirán latentes, aunque en el recuerdo se borren las huellas de la novela o el poema leídos. Con un giro hacia los presupuestos jungianos, para Calvino estas lecturas juveniles «se esconden en los pliegues de la memoria mimetizándose con el inconsciente colectivo o individual».

En defensa del diálogo entre el lector y la obra, planteado sagazmente por Gadamer y por miembros de la Estética de la Recepción, se alista también Harold Bloom (2000: 13) cuando desentraña la paradoja de la lectura como uno de los mayores placeres que proporciona la soledad y el más saludable espiritualmente, que asimismo es un vehículo para que el lector se relacione con la alteridad y encuentre alivio del aislamiento. En «Breve discurso sobre la cultura», Mario Vargas Llosa (2010) da un paso más al apostillar que leer ciertos libros que pasan de generación en generación supone un hermanamiento con los lectores de épocas idas, quienes, como el lector actual, gozaron y soñaron con los textos que conforman nuestro legado. Para él, la cultura es el espacio que posibilita la comunicación entre seres humanos pese a las diferencias de lenguas, creencias y épocas; es un espacio de diálogo. Afirma que el sentimiento de pertenencia a la colectividad humana a través del tiempo y del espacio es el más alto logro de la cultura y nada contribuye tanto a renovarlo en cada generación como la literatura. El libro se erige como defensa de la inteligencia y de la capacidad humana para expresar pensamientos y emociones. No obstante, también es una amenaza para quienes intentan limitarlo (Torre Villar, 1999); de ahí la censura, las quemas de bibliotecas e incluso la desidia lectora en los programas de enseñanza.

En la conferencia «El lenguaje de la identidad», Emilio Lledó (2013) parafraseaba la idea de Aristóteles de que los seres humanos realmente lo somos porque emitimos palabras que tienen sentido y que son el principal instrumento de aprendizaje. Alude a los escritores en términos de mediadores entre el individuo y el amplio mundo, y los tilda de mecenas del diálogo productivo en tanto que son capaces de sacarnos de nuestra cotidianeidad y abrir los espacios de la imaginación, rompiendo «ese monólogo que somos» y transformándolo en un diálogo que reconforta, enseña, orienta y da libertad. Para él, la libertad se construye sobre todo en la escuela y en la universidad. Reclama la responsabilidad sobre la lengua materna como instrumento de comunicación y de pensamiento, además de subrayar la importancia de la lectura en la infancia, que a él mismo lo marcó, contribuyendo a la proyección de sus experiencias posteriores en el ámbito de la creación literaria y de la enseñanza, o en ambas facetas coordinadas.

La literatura nunca es un soliloquio, aunque el diálogo se produzca in distans. Los diferentes tipos de lectores oscilan desde el ingenuo que es atraído por el argumento de la obra y por las 
sensaciones que esta le provoca, hasta el experimentado que posee una preparación que lo faculta para penetrar en los recovecos de las líneas. Algunos escritores dan fe de la búsqueda de ese lector competente. Así, en Confesiones de joven un novelista Umberto Eco (2011) habla de la existencia en sus novelas de una doble codificación a la que da cauce mediante la ironía intertextual, consistente en entreverar sus escritos de citas directas de otros textos famosos o referencias más o menos transparentes a los mismos. También acude a la ironía metanarrativa o reflexiones que el texto hace sobre su propia naturaleza, marca que -considero- prolifera en tal grado en los escritores contemporáneos que constituye un rasgo de la postmodernidad, aunque ambas vías fluyen sin obstáculos en un clásico, el Quijote, desde hace cuatro siglos. La doble codificación permite, según Eco, que la palabra se dirija tanto a una élite capaz de descifrar códigos elevados, como a un público de masas. Ignoro si Eco consigue llegar a estos dos tipos de público en novelas tan extensas y complejas como El nombre de la rosa y El péndulo de Foucault, incluso impulsado a la lectura por la adaptación cinematográfica.

Como ejemplo de la doble codificación, en Vivir para contarla, las memorias de Gabriel García Márquez, el elemento autobiográfico está tamizado por la ficción. Nada más empezar, el escritor evoca el pueblo de su infancia: «Lo recordaba como era: un lugar bueno para vivir, donde se conocía todo el mundo, a la orilla de un río de aguas diáfanas que se precipitaban por un lecho de piedras pulidas, blancas y enormes como huevos prehistóricos» (García Márquez, 2002: 9). Al lector ingenuo tal vez se le escape la peculiar mixtura entre realidad y ficción al presentar el pueblo real con idénticas palabras que el enclave de Macondo en Cien años de soledad. El paisaje real sin duda influyó en la creación del entorno novelesco, pero la audacia radica en invertir el camino al aplicar a tal sitio las palabras ligadas inextricablemente al lugar ficcional. Con ello, y a la manera quijotesca, se difuminan los límites entre la realidad y la ficción, entre la vida y la literatura. Estos guiños o codazos al lector, en terminología de Roland Barthes, se diseminan por la obra provocando la respuesta de un receptor avezado y capaz de reconstruir e interpretar las sugerencias. Páginas adelante, en el paisaje de Aracataca se vislumbra una «vasta ciénaga de aguas turbias y desoladas» (García Márquez, 2002: 13) y un yermo ardiente que linda con una «vasta extensión de aguas verdes con eructos de espuma, donde flotaba todo un mundo de gallinas ahogadas» (2002: 22), frases que remiten asimismo a Cien años de soledad.

Un asunto colateral a las anteriores reflexiones es la selección de obras que ha de ofrecerse y los métodos eficaces para favorecer la lectura, cuestiones que desembocan en los debatidos problemas del canon y en el repertorio de lecturas académicas. Con la irrupción del multiculturalismo en las universidades norteamericanas a partir de los años sesenta del siglo XX, la preponderancia de los clásicos se puso en tela de juicio. A los ataques al tradicional canon occidental por considerarlo europeísta y marginador de comunidades minoritarias han sucedido algunas respuestas que abogan por la importancia capital de la tradición literaria en Occidente. Por ejemplo, Georg Steiner (2011) en Lecciones de los maestros advertía el daño derivado de ensalzar textos de dudosa calidad y ha criticado duramente la institucionalización de pseudoplanes de estudio a costa de 
disciplinas imprescindibles y asimismo la reescritura de la historia hasta llegar a la parodia. Insiste en que la herencia en Occidente es la de Jerusalén, Atenas y Roma -la Biblia y los clásicos-, y que es síntoma de ceguera el rechazo de la literatura occidental por la imposición de forma retroactiva de prejuicios actuales (Steiner, 2011: 150).

Frente a la concepción del canon como repertorio de autores del pasado que funcionan como un modelo para los nuevos escritores y para los lectores, otros intelectuales, desechando el presunto estatismo, argumentan además con la idea de conjunto de textos que suscitan un diálogo continuo, que siguen interrogando, alertando sobre todo tipo de cuestiones y reconfortando (García Gual, 1998). El catálogo no es fijo e intemporal, porque puede ser abordado desde aspectos históricos y subjetivos, en virtud de lo cual es plausible que junto a los clásicos universales se alineen otros nacionales e incluso preferencias personales.

La reflexión sobre el canon conduce hacia la cuestión práctica de la necesidad o no de proponer lecturas obligatorias a los estudiantes y también en este aspecto se alzan voces contrapuestas. Las de tesitura excluyente consideran a la mayoría de los clásicos como materia de erudición y, por lo tanto, sin cabida en la enseñanza, excepto en la especializada. Además, se aferran a la noción de medida ínsita en la acepción griega de canon (Tatarkiewicz, 1993: 240), que rechazan desde una postura contraria a las restricciones. En contrapartida surgen reivindicaciones de los clásicos como entes irremplazables para la formación estética e intelectual de las sucesivas generaciones y, en consecuencia, algunos intelectuales defienden que han de situarse en el corazón del sistema educativo. No faltan las posturas intermedias, por lo común eclécticas, que matizando el supuesto dogmatismo y la rigidez, abogan por tener en cuenta factores como la relación entre las obras y la edad de los lectores (Sylveira, 2008; Cerrillo, 2010; Cerrillo, 2013), la conveniencia de las adaptaciones y la operatividad de la mezcla de obras de distinto tipo.

En un libro muy reciente, Las letras entornadas (2015), Fernando Aramburu aduce con una buena dosis de ironía que en la ciudadanía actual democrática y tolerante se acepta la imposición de determinadas disciplinas en la enseñanza (el manejo en matemáticas, los idiomas, aspectos de las ciencias...), pero «leer a la fuerza es una aberración» (Aramburu, 2015: 25). Para contrarrestar esta opinión, rememora los primeros libros que entraron en su casa, por orden de un profesor a quien dedica «ráfagas de agradecimiento» porque fueron una primera puerta al conocimiento de la lengua alta. Señala que «la imposición de la lectura, por sí sola no hace lectores, de la misma manera que un niño arrojado al mar no se convierte al instante en nadador. Sin embargo, es innegable que una vez dentro del agua aumentan las posibilidades de aprender a leer» (Aramburu, 2015: 24). Aconseja métodos que favorezcan la lectura, como la declamación en público y el intercambio de experiencias letradas hasta ir formando «una comunidad lectora» (Aramburu, 2015: 28).

Por su parte, en una entrevista titulada «Luis Landero: la fascinación por el lenguaje», el novelista recuerda con nombre y apellidos al maestro que le enseñó a leer y a escribir, y también al profesor de literatura de PREU que le ayudó a educar la sensibilidad estética y a reorientar los gustos literarios (Landero, 2008: 136). Apunta los procedimientos con que él mismo, en su faceta de 
docente, atrae a los estudiantes hacia la lectura, algunos de los cuales (la recitación) son similares a los citados por Aramburu (Landero, 2008: 136). Denuncia la trampa de ocultar el esfuerzo que supone la adquisición de hábitos de lectura y de un nivel cultural, aunque tal trabajo no excluya la amenidad, el gozo e incluso el postrer agradecimiento. Landero aconseja que se conserve el hábito de dedicar en el aula una hora o más a la lectura y otra a la escritura, atendiendo a la comprensión del contenido; en definitiva «mucha práctica, mucho leer y mucho escribir. Con la ventaja de que, siendo la literatura el patio de vecindad de las humanidades, leyendo se aprende mucho por añadidura» (Landero, 2008: 137). Se muestra poco restrictivo respecto a los libros recomendados para leer en grupo académico, pero para la lectura particular aconseja obras amenas o fragmentos si presentan mucha dificultad. Con una metáfora gastronómica de ascendencia tradicional -la palabra es el alimento del espíritu-, propone asimismo las «lecturas a la carta»: «De primero un libro de poemas a elegir entre 10 o 12. De segundo, una novela o una obra de teatro a elegir entre 3 o 4 . De postre, lo que cada cual quiera» (Landero, 2008: 137).

Según Italo Calvino (1996), la escuela debe dar a conocer a cierto número de clásicos, que servirán de brújulas que orienten las posteriores lecturas desinteresadas e incluso el hallazgo del clásico personal que se sitúa como eje de referencia estética y a veces vital. Para muchos escritores el acercamiento a los clásicos es adecuado porque su carga simbólica universal y la capacidad de entablar un diálogo en la distancia vencen el tempus aedax rerum. Para Aramburu (2015: 33), los clásicos se mantienen vigentes porque guardan en su entraña las cuestiones inmarcesibles y esenciales. En este aspecto, entre los géneros literarios destaca la poesía, pese a su recepción minoritaria sobre todo en el mundo contemporáneo. Escribe:

El yo del poeta se caracteriza por su naturaleza universal. Cuando el personaje de una novela o el de una pieza de teatro dicen yo, por fuerza se refieren a sí mismos en cuanto seres singulares, únicos, irrepetibles. Cuando lo dice el poeta en el poema, entonces el pronombre personal se lo puede calzar quienquiera, por ejemplo el que lee o el que escucha, lo mismo ahora que dentro de cien años. En cierto modo el poeta expresa la intimidad de la especie, y eso sin que los elementos constitutivos del poema dejen de ser una representación simbólica de lo que él piensa, siente, etc. Tiene razón Schopenhauer. El poeta es el ser humano general. En él se expresa un yo de baja densidad anecdótica, despojado de rasgos singulares aunque haga manar la poesía desde el fondo de su intimidad; un yo, por tanto, susceptible de ser transferido a toda la especie. Es por ello razonable que un poema pueda servir de letra a himnos nacionales, canciones del pueblo o, en fin, a cualquier manifestación del sentido colectivo (Aramburu, 2015: 138).

Roza una cuestión teórica que se ha planteado históricamente con diferentes enfoques desde la distinción aristotélica entre historia y poesía. En períodos contemporáneos se han establecido como rasgos genéricos de la lírica la preeminencia de espacios de indeterminación enunciativa y la supremacía del presente como tiempo en el que confluyen las vivencias del emisor y del receptor. El vacío de referencias concretas, diáfano en los pronombres -el tú y el yo, claves en lírica- propicia una gran apertura y favorece la identificación del lector con los contenidos (Pozuelo Yvancos, 2009). Otros géneros también participan de esa «naturaleza universal», aunque de manera menos evidente.

En el artículo titulado «Necesidad de la literatura», Emilio Lledó (2002) esgrime una vehemente defensa de los clásicos que basa en su paradójica cercanía para convocarnos y avivarnos. 
Desde la página de la escritura se incorporan al presente y nos ofrecen un diálogo (de nuevo este concepto axial) en términos de «indefinible amistad». Todo ello va inextricablemente ligado a la función de la literatura antes mencionada: ser una privilegiada vía de conocimiento que abarca el presente y el pasado, ofrecidos desde focos muy poderosos e iluminadores. Aduce:

La lectura, los libros, son el más asombroso principio de libertad y fraternidad [...] En las letras de la literatura entra en nosotros un mundo que, sin su compañía, jamás hubiéramos llegado a descubrir. Uno de los prodigios más asombrosos de la vida humana, de la vida de la cultura, lo constituye esa posibilidad de vivir otros mundos, de sentir otros sentimientos, de pensar otros pensares que los reiterados esquemas que nuestra mente se ha ido haciendo en la inmediata compañía de la triturada experiencia social y sus, tantas veces, pobres y desrazonados saberes.

Dada la reflexividad de la literatura, algunas obras proponen un nuevo tipo de práctica lectora. Por ejemplo, para Carlos Fuentes (2006: 18) el Quijote consiguió alterar profundamente las tradiciones heredadas sobre la lectura y la escritura y modificó a su vez la cultura de su propio presente e incluso del futuro. La clave radicó en insertar la crítica de la creación dentro de la misma creación y proyectar una lectura metaliteraria.

En relación con los clásicos cabe señalar que, según presupuestos tradicionales, la relevancia de un escritor se mide por la huella que deja en otros escritores y en los múltiples lectores. Harold Bloom (2013) la establece por su dependencia con los precursores y, en consecuencia, su concepto de lectura se vincula a la capacidad de relacionar la letra que se recibe con otras previas. Leer supone sumergirse en el cauce de unas obras que siempre remiten a otras, de escuchar las voces y los ecos en una inabarcable polifonía. No es preciso que todos lo adviertan en la misma medida que el lector competente, pero siempre quien lee recibe esponjado en su interior el líquido del cauce. En tales presupuestos confluyen parcialmente teorías literarias de variado signo, desde la los conceptos de repertorio de Iser hasta las definiciones de intertextualidad e hipertexto.

La imagen de fluencia acuática representa la teoría clasicista del avance de la literatura, cuyo contenido también enunciada el tópico que tilda a los nuevos escritores como enanos encaramados en hombros de gigantes. Italo Calvino (1996) traslada estos presupuestos al ámbito del emisor cuando sutilmente desliza la idea de que el escritor es un lector y, sumándose al concepto de fluencia literaria, anota: «Los clásicos son esos libros que nos llegan trayendo la huella de las lecturas que han precedido a la nuestra, y tras de sí la huella que han dejado en la cultura o en las culturas que han atravesado (o más sencillamente, en el lenguaje o en las costumbres)» (Calvino, 1996: 34).

Un asunto colateral es la transmisión del sentido de los textos. En Los límites de la interpretación Umberto Eco (1992) distingue entre intentio auctoris o intención que el autor desea transmitir con su obra, intentio lectoris o posibilidad de entendimiento de esta según los lectores, e intentio operis, referida a la potencialidad de significados que guarda la obra («un clásico es un libro que nunca termina de decir lo que tiene que decir» recordaba Italo Calvino). El texto suscita interpretaciones, provocando al lector, pero -según Eco- especialmente en la lectura académica el texto de base legitimará una lectura determinada. Han de rellenarse los «huecos de lectura», pero respetando lo que Roman Ingarden denominaba «formación esquemática» en la que varios de los 
estratos, especialmente el de las objetividades proyectadas y el de los aspectos, contienen «puntos de indeterminación» que se irán eliminando progresivamente en los actos de lectura concretos. Aclara Ingarden que en el proceso de rellenar los puntos de indeterminación operan los factores determinantes del objeto y pueden variar de concretización a concretización (Ingarden, 2005: 28). Las posibilidades de comprensión cambian según se trate de lectores doctos o toscos, y también dependen de las épocas, porque cada comunidad de lectores define unos modos de leer y unos procedimientos de interpretación (Cavallo y Chartier, 1998: 13).

Con independencia del debate teórico, en la práctica académica -según Steiner en Presencias reales - el profesor de literatura se comporta como un intérprete, un descifrador y un comunicador de significados; por lo tanto, es un traductor entre lenguajes y entre culturas. Al tratar el material con el que se enfrenta, le infunde vida inteligible (Steiner: 2007: 3). Curiosamente en una época que ha despreciado la memoria, desde posturas conservadoras Steiner clama por el cultivo de la misma en relación con la forja de la identidad cultural de los individuos y con la preservación del patrimonio espiritual $^{2}$. En Lecciones de los maestros, Steiner (2011) es sumamente explícito:

En general, lo que sabemos de memoria madurará y se desarrollará con nosotros. El texto memorizado se interrelaciona con nuestra existencia temporal, modificando nuestras experiencias y siendo dialécticamente modificado por ellas. Cuanto más fuertes sean los músculos de la memoria, mejor protegido está nuestro ser integral. Ni el censor ni la policía pueden arrancarnos el poema recordado (testimonio, la supervivencia de boca en boca, de los poemas de Mandesltam, de los cuales no era factible ninguna versión escrita). Se sabe que, en los campos de exterminio, algunos rabinos y estudiosos talmúdicos eran libros vivientes, cuyas páginas, que contenían la totalidad de sus recuerdos, podían pasar otros prisioneros en busca de juicio o consuelo. La gran literatura épica, los mitos fundacionales, comienzan a declinar con el progreso del paso a la escritura. Por todas estas razones, la eliminación de la memoria en la escolarización actual es una desastrosa estupidez. La conciencia está tirando por la borda su lastre vital (Steiner, 2011: 37).

Al considerar que la literatura modifica nuestra experiencia, roza la tesis de la función perlocutiva, que los existencialistas y los autores comprometidos dejaban traslucir en el lema de «la palabra es un arma». Por su parte, en el famoso artículo «La muerte de autor», Barthes (1987) modulaba el concepto de performatividad de Austin cuando señalaba que quien realiza la acción a través de las palabras no es el autor sino el lector, pues este, mediante la lectura, construye y encarna en su presente aquello que se ha escrito. Asimismo, con la lectura el texto se hace realidad como experiencia de quien lo lee. Barthes revelaba un rasgo más de lo performativo: las palabras producen una subjetividad, una forma concreta de ser consciente y de entender el mundo; en el fondo, modifican el ser.

Retornando a la memoria, Steiner recalca que su importancia radica en ser medio de protección de la identidad y custodio de la historia personal y colectiva. Por otro lado, expone otro de

\footnotetext{
${ }^{2}$ Escribe: «Lo aprendido de memoria y susceptible de rememoración constituye el lastre del yo. Las presiones de la exacción política y la marca detergente de la conformidad social no pueden apartarlo de nosotros. En soledad, tanto si es pública como si es privada, el poema recordado o la partitura tocada en nuestro interior son los custodios y los recordadores [...] de lo que es resistente, de lo que debe ser mantenido sin mancillar en nuestra psique» (Steiner, 2007: 4).
} 
los fines tradicionales de la literatura: servir de consuelo y terapia en tanto que proporciona referencias que orientan sobre el estado de los individuos en comparación con otros casos. Aunque en la actualidad se relega la memoria, con el peligro que ello comporta, en compensación se abren inauditos canales de comunicación literaria ligados a la red y a los soportes electrónicos. Estos accesos aproximan las obras literarias al lector, pero también contribuyen a relajar el respeto por la literalidad de los textos clásicos y contemporáneos. La profusa información y la ausencia de criterios de selección pueden crear un caos. La desconfianza posmoderna en los universales es paralela al recelo que suscitan los clásicos. Terry Eagleton (2013: 25) plantea que en la modernidad los objetos del mundo se definen «en términos de cómo reaccionan nuestros procedimientos y técnicas, mientras que la cuestión de cómo son [las cosas] en sí mismas se pierde en el horizonte de nuestra cognición». Indica:

Como en el océano de Solaris, de Lem, el mundo ha dejado de tener rasgos, se ha vuelto esquivo y, en última instancia, ininteligible. ¿Es el precio de la libertad la pérdida de la realidad? En cualquier caso, si el yo no tiene ninguna esencia -si no es más que una función de poder, una recopilación caótica de impresiones sensoriales, una entidad netamente fenoménica, un proceso discontinuo o un fruto del inconsciente-, entonces ¿quién es el agente de esta transformación del mundo y a quién sirve? En esta configuración escénica desoladora, un sujeto absoluto se enfrenta a un mundo puramente contingente (2013: 25).

Con ecos de planteamientos marxistas, Eagleton saca a relucir otro de los atractivos de la literatura, que se relaciona con sus funciones capitales: porta una rebeldía intrínseca, es el «último reducto de lo particular», de lo díscolo y de la destrucción de la visión unitaria y esquematizada de la realidad (Eagleton, 2103: 36). Según Eagleton, el estructuralismo y el posmodernismo forman el último capítulo de la historia del nominalismo. Para él, Foucault, Derrida y Deleuze con su aversión al concepto general y al principio universal son herederos de determinados escolásticos de la Edad Media. Eagleton refuta estas premisas indicando que aunque muchas obras presenten enormes diferencias entre sí, también existen continuidades y rasgos comunes con tanta fuerza histórica como la diferencia y la discontinuidad (Eagleton, 2013: 39). Retoma las teorías que Wittgenstein expuso en Investigaciones filosóficas acerca del problema de la diferencia y la identidad. Al fin y al cabo busca perfilar qué es la literatura cuando señala varias categorías empíricas o factores (ficcional, lingüístico, no pragmático y normativo) que confluyen en lo literario y que pueden aparecer en conjunto o parcialmente. Al apuntar a la confluencia de estos elementos dirige la flecha a los clásicos:

Cuanto mayor sea el número de estos factores que se den cita en un texto concreto, más probable es que en nuestra cultura alguien lo califique de literario. [...] Los textos que aúnan todos estos factores (Otelo o Luz de agosto) se suelen tomar como paradigmas de lo literario. Pero ninguna obra calificada de literaria tiene que satisfacer todos los criterios, y la ausencia de alguno no tiene por qué bastar para desbancarla de la categoría. En este sentido, ninguno de estos atributos es una condición necesaria del estatus literario (Eagleton, 2013: 53). 


\section{Referencias bibliográficas}

Aullón de HARO, P. (2013): Escatología de la crítica. Madrid, Dykinson.

BARTHES, R. (1987): «La muerte de autor», en El susurro del lenguaje. Barcelona, Paidós.

Bloom, H. (2000): Cómo leer y por qué. Barcelona, Anagrama.

(2013): Novelas y novelistas. El canon de la novela. Madrid, Páginas de Espuma.

Calvino, I. (1993): Por qué leer a los clásicos. Barcelona, Tusquets (Marginales).

Cerrillo, P. C. (2010): «Lectura escolar, enseñanza de la literatura y clásicos literarios», en G.

LLUCH, ed., Las lecturas de los jóvenes. Un nuevo lector para un nuevo siglo. Barcelona, Anthropos, 85-104.

- (2013): «Canon literario, canon escolar y canon oculto». Quaderns de Filologia. Estudis literaris, XVIII, 17-31.

CRespo de las Heras, S. y Del AmOR Del Amo, M. C. (2008): «Luis Landero: la fascinación por el lenguaje». CEE Participación Educativa, 8, 134-138.

EAgleton, T. (2013): El acontecimiento de la literatura. Barcelona, Península.

EcO, U. (1992): Los límites de la interpretación. Barcelona, Lumen.

(2011): Confesiones de un joven novelista. Barcelona, Lumen.

FuENTES, C. (2006): Cervantes o la crítica de la lectura. Madrid, Centro de Estudios Cervantinos.

Gallego, V. (2012): Mundo dentro del claro. Barcelona, Tusquets.

García Gual, C. (1998): «Leer a los clásicos». Nueva Revista de Política, Cultura y Arte, 058.

GraCiÁn, B. (1969): Agudeza y arte de ingenio. Madrid, Castalia.

INGARDEN, R. (2005): La comprehensión de la obra de arte literaria. Ciudad de México, Universidad Iberoamericana.

LLEDÓ, E. (2002): «Necesidad de la literatura», El País, 21 de diciembre.

- (2013): «El lenguaje de la identidad», LcLibros.com

Martos Núñez, E., CAMPos Fernández Figares, M., coords. (2013): Diccionario de nuevas formas de lectura y escritura. Madrid, Santillana.

Pozuelo Yvancos, J. M. (2009): Poéticas de poetas. Teoría, crítica y poesía. Madrid, Biblioteca Nueva.

RAMÍREZ LEYVA, E., coord. (2015): Tendencias de la lectura en la universidad. México, UNAM.

SEnABRE, R. (2015): El lector desprevenido. Oviedo, Nobel.

SKLOVSKI, V. (1991): «El arte como artificio», en T. TOdOROV, Teoría de la literatura de los formalistas rusos. México, Siglo XXI, pp. 55-70.

SteIner, G. (2001): Después de Babel. Aspectos del lenguaje y la traducción. México, Fondo de Cultura Económica.

- (2007): Presencias reales. Barcelona, Destino.

- (2011): Lecciones de los maestros. Madrid, Siruela.

SylveIRA, C. (2008): «Los clásicos a su debido tiempo». SOL. Servicio de Orientación de Lectura, en http://cervantesvirtual.com/nd/ark:/59851/bmc02995 (última consulta, 23-2-2016). 
Tropelías. Revista de Teoría de la Literatura y Literatura Comparada, número extraordinario 2 (2017) 61

Los clásicos en la formación lectora. Testimonios de escritores

TATARKiEWiCZ, W. (1993): «Creación: historia del concepto», Criterios, 30, 238-257.

TORRE VILlar, E. de la. (1999): Elogio y defensa del libro. México, UNAM.

VARGAS LlOSA, Mario. (2010): «Breve discurso sobre la cultura», Letras libres, 12, 139, 48-55. 